\title{
Survey of Access to GastroEnterology in Canada: The SAGE wait times program
}

\author{
Desmond Leddin $\mathrm{MB}^{1}$, Ronald J Bridges $\mathrm{MD}^{2}$, David G Morgan $\mathrm{MD}^{3}$, Carlo Fallone $\mathrm{MD}^{4}$, Craig Render $\mathrm{MD}^{5}$, \\ Victor Plourde $M D^{6}$, Jim Gray $M D^{7}$, Connie Switzer $M D^{8}$, Jim $M c H$ attie $M D^{9}$, Harminder Singh $M D^{10}$, \\ Eric Walli $M D^{10}$, lain Murray MD ${ }^{11}$, Anthony Nestel MD ${ }^{12}$, Paul Sinclair MSc ${ }^{13}$, Ying Chen MSc ${ }^{3}, E$ Jan Irvine MD $^{14}$
}

D Leddin, RJ Bridges, DG Morgan, et al. Survey of Access to GastroEnterology in Canada: The SAGE wait times program. Can J Gastroenterol 2010;24(1):20-25.

BACKGROUND: Assessment of current wait times for specialist health services in Canada is a key method that can assist government and health care providers to plan wisely for future health needs. These data are not readily available. A method to capture wait time data at the time of consultation or procedure has been developed, which should be applicable to other specialist groups and also allows for assessment of wait time trends over intervals of years.

METHODS: In November 2008, gastroenterologists across Canada were asked to complete a questionnaire (online or by fax) that included personal demographics and data from one week on at least five consecutive new consultations and five consecutive procedure patients who had not previously undergone a procedure for the same indication. Wait times were collected for 18 primary indications and results were then compared with similar survey data collected in 2005.

RESULTS: The longest wait times observed were for screening colonoscopy (201 days) and surveillance of previous colon cancer or polyps (272 days). The shortest wait times were for cancer-likely based on imaging or physical examination ( 82 days), severe or rapidly progressing dysphagia or odynophagia (83 days), documented irondeficiency anemia (90 days) and dyspepsia with alarm symptoms (99 days). Compared with 2005 data, total wait times in 2008 were lengthened overall (127 days versus 155 days; $\mathrm{P}<0.05)$ and for most of the seven individual indications that permitted data comparison.

CONCLUSION: Median wait times for gastroenterology services continue to exceed consensus conference recommended targets and have significantly worsened since 2005.

Key Words: Access; Audit; Diagnosis; Endoscopy; Gastroenterology; Wait time

ssessment of wait times pertaining to specialist referrals Aremains a key method for determining the availability of health care in Canada. Previous studies indicating excessive wait times for a variety of specialties $(1,2)$ have prompted government organizations to establish benchmarks for medically acceptable wait times in a number of medical fields (3).

The federal Wait Time Alliance, of which the Canadian Association of Gastroenterology (CAG) is a member, has

\section{Sondage sur l'accès à la gastro-entérologie au Canada : Programme SAGE sur les temps d'attente}

HISTORIQUE : Le calcul des temps d'attente actuels pour l'accès aux services de santé spécialisés au Canada est une méthode clé pour aider les gouvernements et les professionnels de la santé à planifier judicieusement en vue des besoins futurs en matière de santé. Ces données ne sont pas faciles à établir. Une méthode a été mise au point pour calculer les intervalles avant les consultations ou les interventions. Cette méthode serait applicable à d'autres spécialités et permet d'évaluer les tendances en matière de temps d'attente pour des intervalles calculés en années.

MÉTHODE : En novembre 2008, des gastro-entérologues des quatre coins du Canada ont été invités à répondre à un questionnaire (en ligne ou par télécopieur) qui incluait des données démographiques personnelles et des données pour une période d'une semaine sur au moins cinq nouvelles consultations et cinq interventions consécutives chez des patients qui n'avaient encore jamais subi d'intervention pour la même indication. Les temps d'attente ont été recueillis pour 18 indications principales et les résultats ont ensuite été comparés aux données d'un sondage similaire effectué en 2005

RÉSULTATS : Les temps d'attente les plus longs observés concernaient la colonoscopie de dépistage (201 jours), le suivi d'un cancer ou des polypes du côlon (272 jours). Les temps d'attente les plus courts concernaient les cas de cancers probables selon les résultats de l'imagerie ou de l'examen physique ( 82 jours), la dysphagie ou l'odynophagie graves ou progressant rapidement ( 83 jours), l'anémie ferriprive documentée ( 90 jours) et la dyspepsie avec symptômes alarmants (99 jours). Comparativement aux données de 2005, les temps d'attente totaux en 2008 ont augmenté dans l'ensemble (127 jours, contre 155 jours, $\mathrm{P}<0,05)$ dans la plupart des sept indications pour lesquelles la comparaison a pu être effectuée.

CONCLUSION : Les temps d'attente médians en gastro-entérologie continuent d'excéder les cibles recommandées par la Conférence consensuelle et se sont significativement aggravés depuis 2005 .

sought to reduce wait times for health care across Canada (4). The benchmarks for gastroenterology (time to consultation or procedure, if indicated) that were developed at a 2005 consensus conference are that emergency cases should be seen within $24 \mathrm{~h}$, urgent cases should be seen within two weeks, semi-urgent cases should be seen within two months and routinely scheduled cases should be seen within six months (Table 1) (4,5).

${ }^{1}$ Dalhousie University, Halifax, Nova Scotia; ${ }^{2}$ University of Calgary, Calgary, Alberta; ${ }^{3}$ McMaster University, Hamilton, Ontario; ${ }^{4}$ McGill University, Montreal, Quebec; ${ }^{5}$ Kelowna General Hospital, Kelowna, British Columbia; ${ }^{6}$ Centre hospitalier de l'Université de Montréal, Montreal, Quebec; ${ }^{7}$ University of British Columbia, Vancouver, British Columbia; ${ }^{8}$ University of Alberta, Edmonton, Alberta; ${ }^{9}$ Regina General Hospital, Regina, Saskatchewan; ${ }^{10}$ University of Manitoba, Winnipeg, Manitoba; ${ }^{11}$ Intestinal Health Institute, Markham, Ontario; ${ }^{12}$ South Shore Regional Hospital, Bridgewater, Nova Scotia; ${ }^{13}$ Canadian Association of Gastroenterology, Oakville; ${ }^{14}$ University of Toronto and St Michael's Hospital, Toronto, Ontario

Correspondence: Dr Desmond Leddin, Dalhousie University, Division of Gastroenterology, Room 912, Victoria Building, Victoria General Hospital Site, 1278 Tower Road, Halifax, Nova Scotia B3H 2Y9. Telephone 902-473-7833, fax 902-473-4406, e-mail desmond.leddin@dal.ca

Received for publication October 13, 2009. Accepted October 23, 2009 
A previous audit of wait times in gastroenterology in Canada - the Practice Audit in GastroEnterology (PAGE) program - was performed almost four years ago (6). Conducted between January and October 2005, the PAGE program documented median wait times from referral to consultation and/or procedure for patients with digestive diseases. A comparison of the real-world wait times in gastroenterology reported in PAGE and the consensus recommended wait times (5) found that the total wait times across seven indications exceeded published recommendations in $51 \%$ to $88 \%$ of cases, including both urgent and nonurgent cases (7).

One of the key factors affecting wait times in gastroenterology is the actual number of specialists available. A work force analysis conducted in 2007 found that there were 1.83 gastroenterologists per 100,000 population in Canada compared with almost twice that in the United States $(3.9$ per 100,000$)$ and France $(3.48$ per 100,000 ) (8). Furthermore, as the population of Canada continues to shift toward an older mean age, the greater prevalence of acute and chronic health concerns in older patients will further increase the demand for services. This will undoubtedly create a greater negative impact on already long wait times if no additional resources are allocated and/or services are not redesigned.

The aim of the present study was to survey and report the national wait times for specialist gastroenterology care, and to examine change over time, if any, from the previous assessment (ie, PAGE) conducted in 2005.

\section{METHODS}

The CAG National Office managed all administrative aspects of the program. A special advisory committee (DL, EJI, CF, CR) with expertise in gastroenterology care, was integrally involved in all aspects of the program, including concept development, practice audit logistics management, data reporting and data analysis.

\section{Participants}

Physicians who specialize in digestive diseases (adult and pediatric gastroenterologists, and internists specializing in gastroenterology) were informed in advance of the survey through mailed announcements to CAG members and provincial gastroenterology organizations, as well as through advertisements in monthly e-newsletters, and notices published in The Canadian Journal of Gastroenterology and posted on the CAG Web site. Gastroenterologists or internists who were not CAG members were identified through the Canadian Medical Directory and also invited to participate. The CAG also liaised with the provincial and regional gastroenterology physician societies to encourage them to advertise and promote the program to their memberships. Physicians were encouraged to register their intent to participate with the CAG National Office using e-mail, telephone or fax.

Physicians were asked to provide personal demographic data and anonymous information on at least five new consecutive clinic patients (consults) and five consecutive procedure patients who had not had a previous procedure for the same indication. Only new referrals were included. Patients who were seen for urgent or nonurgent same-day consultation and procedure $(C \& P)$ were included and analyzed separately. Patients presenting to the emergency room were excluded.

\section{TABLE 1}

\section{Overview of maximal wait times by selected acuity} categories

Within two weeks
High likelihood of cancer based on imaging or physical examination
Severe and/or rapidly progressive dysphagia or odynophagia
Clinical features suggestive of acute inflammatory bowel disease
Within two months
Bright red rectal bleeding
Documented iron-deficiency anemia
One or more positive fecal occult blood tests
Chronic viral hepatitis
Stable dysphagia (not severe)
Poorly controlled reflux/dyspepsia
Chronic constipation or chronic diarrhea
New-onset change in bowel habits
Chronic, unexplained abdominal pain
Confirmation of a diagnosis of celiac disease (antibody test)
Within six months
Chronic gastroesophageal reflux disease for screening endoscopy
Screening colonoscopy
Persistent (>6 months) unexplained abnormal liver enzyme tests

Data are adapted from reference 5

\section{Questionnaire}

The Survey of Access to GastroEnterology (SAGE) questionnaire was developed by an advisory committee with expertise in gastroenterology, education, clinical research and previous national audit projects. It was designed to provide a snapshot of wait times related to 18 selected indications based on the Canadian consensus on medically acceptable wait times for digestive health care (5) as well as an 'other' write-in category. After review of the 'other' indications, many were found to relate to surveillance of colon cancer or colon polyps - these were grouped into indication 20, while those remaining became indication 19 (other, most of which were biliary in nature). Some items included in the questionnaire were similar to those collected in a previous survey conducted in 2005. New items were added to evaluate changes in the scope of practice that had occurred since 2005 and to apply to a broader sample of the provider population. Physicians were first asked to answer eight demographic questions describing their practice (Table 2), then to provide data for consecutive new patients (Table 3) seen during the week of November 17 to 21, 2008 (or, alternatively, weeks November 10 to 14 or November 24 to 28, 2008). Information was collected using a commercial online survey Web site (www.surveymonkey.com) or single-page fax form available in English or French. To ensure that the questionnaire was understandable, it was administered to a small convenience sample of physicians before the final survey date.

\section{Ethics review}

In the present survey, patient identifiers were not collected (ie, patient names and their information remained anonymous), no patient intervention was involved, only aggregate results were subsequently reported and, overall, minimal data were collected. Although these factors do not neccesitate an ethics review, this quality assurance/practice audit program was approved by a central ethics committee (Institutional Review Board, August 2008). Separate ethics approval was obtained in Alberta. 


\section{TABLE 2}

\section{Survey of Access to GastroEnterology (SAGE) - clinician demographics}

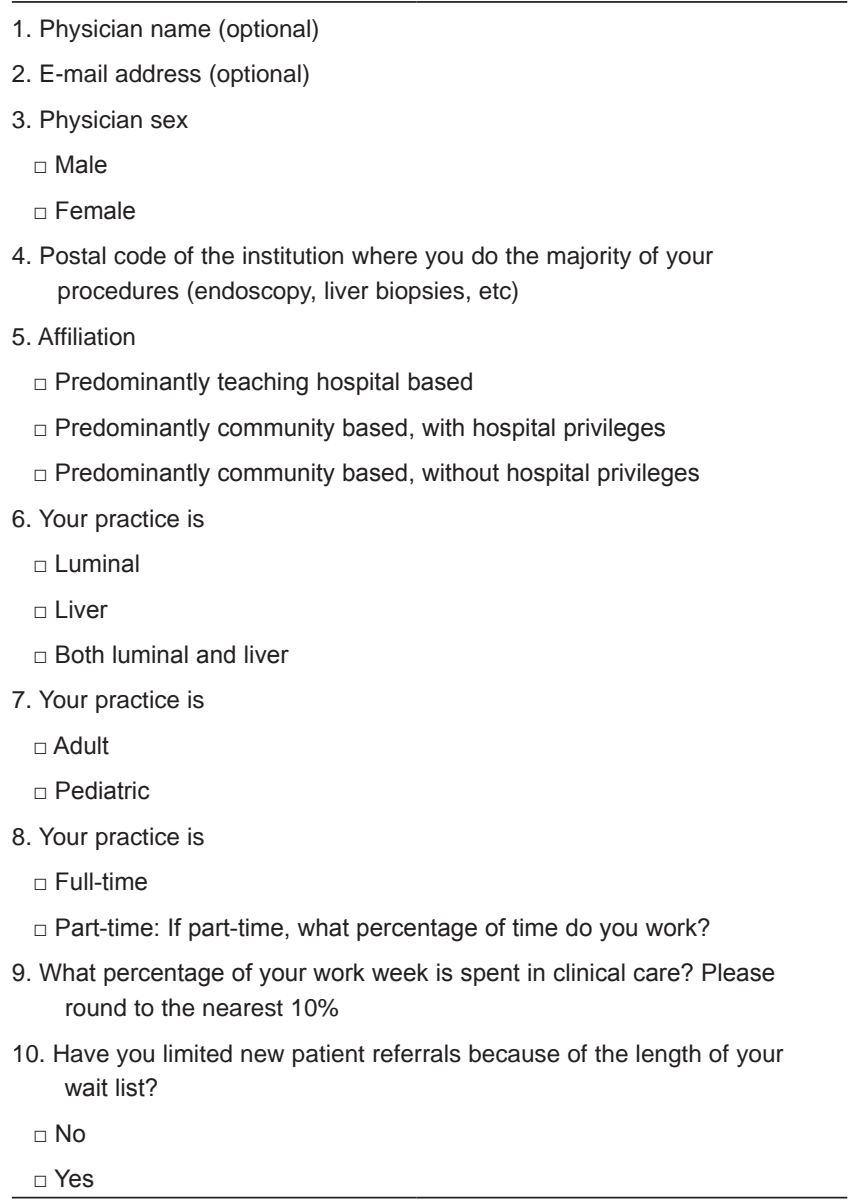

\section{Data analysis}

An independent data analysis was conducted and statistical support was provided by the Division of Gastroenterology at McMaster University (Hamilton, Ontario) (YC). Statistical analyses, performed using SAS version 9.2 (SAS Institute Inc, USA), generated the following wait time durations:

1. The wait time to consultation: Time from the patient's first referral to the digestive health care provider until the consultation;

2. The wait time to procedure: Time from the patient's first consultation with the digestive health care provider until the completion of the digestive disease procedures or tests; and

3. The total wait time: Time from the patient's first referral to the digestive health care provider until completion of the procedures or tests. Total wait time is available only for patients who had both a consult and a procedure.

Data for patients undergoing same-day C\&P were analyzed separately. Data from the 2005 PAGE survey were re-analyzed to provide analyses of new patients only and same-day C\&P.

Wait times are presented as medians with 95\% CIs. Statistical comparisons with data from the PAGE program were performed using Wilcoxon's rank-sum test.
TABLE 3

Survey of Access to GastroEnterology (SAGE) - patient information

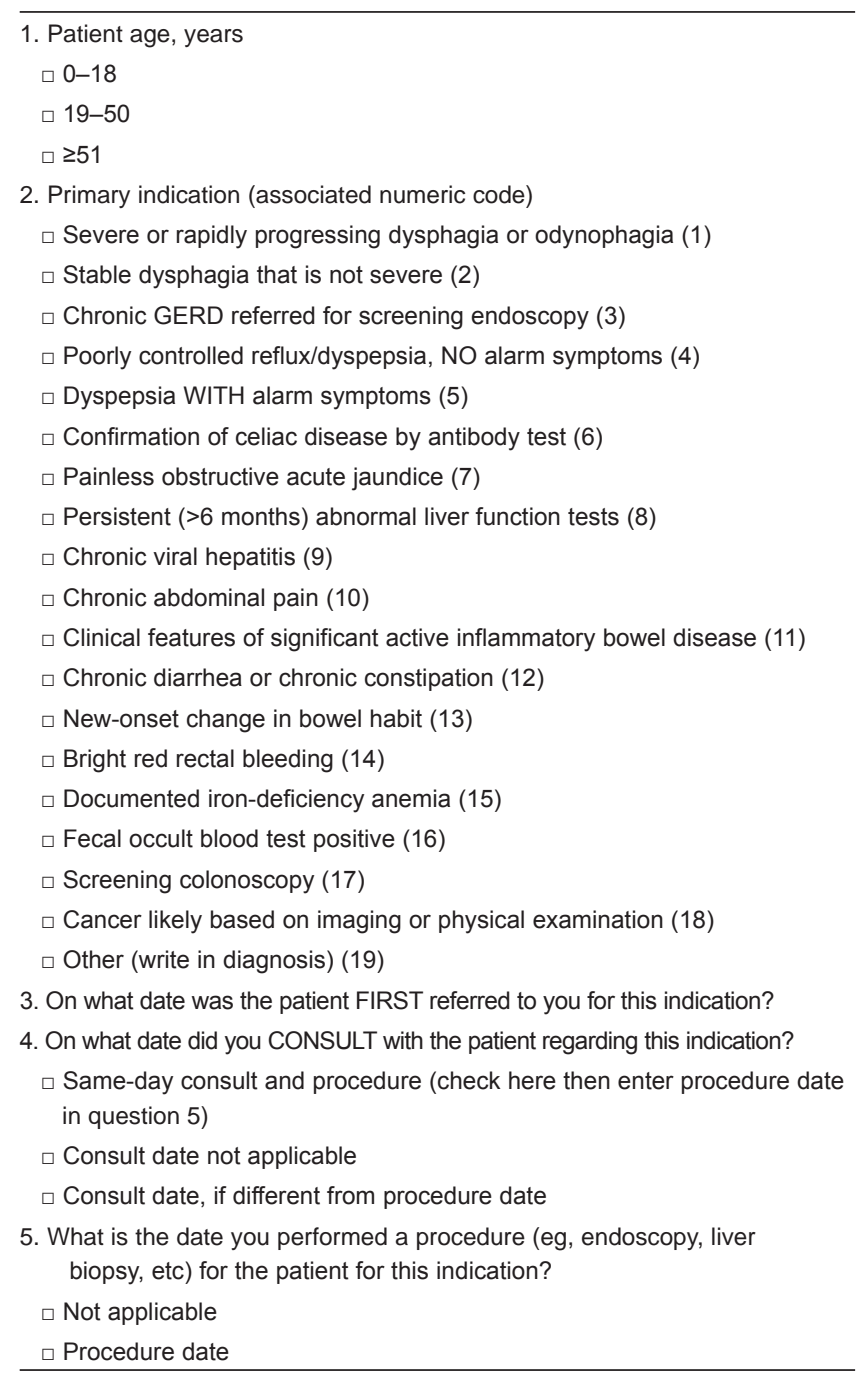

GERD Gastroesophageal reflux disease

\section{Participants}

\section{RESULTS}

During November 2008, 226 physicians of an estimated 550 (8) who were either gastroenterologists or internists practicing gastroenterology in Canada participated in the one-week survey. Of the 226 physicians, 17 (7.5\%) were pediatric gastroenterologists ; however, the present analysis includes data on adult patients only. The greatest proportions of participants were from Ontario (38.1\%), followed by Quebec (15.5\%), Alberta (15.5\%), British Columbia (13.3\%), Nova Scotia (4.4\%), Manitoba (4.0\%), Saskatchewan (2.7\%), Newfoundland (2.7\%), New Brunswick (2.2\%) and Nunavut/ Northwest Territories (0.9\%).

Participating physicians were predominantly male $(n=183$, 81.0\%), full-time $(\mathrm{n}=211,93.4 \%)$, adult gastroenterologists $(\mathrm{n}=209,92.5 \%)$. Of the responding clinicians, 50.9\% $(\mathrm{n}=115)$ were affiliated with a teaching hospital, $45.1 \%(n=102)$ were community-based with hospital privileges and $3.5 \%(n=8)$ were community-based without hospital privileges. Most practices $(\mathrm{n}=162,71.7 \%)$ specialized in both luminal and liver diseases, 
while $27.0 \%(n=61)$ specialized only in luminal and $1.3 \%$ $(n=3)$ only in liver diseases. Approximately $74.3 \%(n=168)$ of participants indicated that they spend more than $70 \%$ of their work week in clinical care. Almost one-third of physicians $(n=74,32.7 \%)$ were limiting new patient referrals.

\section{Overall wait times}

Data on 1824 consultations, 741 procedures and 436 sameday C\&Ps were collected. Nationally, the median wait times to consultation and to procedure were 92 days (95\% CI 87 to 97 days) and 50 days (95\% CI 45 to 55 days), respectively, while the median total wait time for both was 155 days $(95 \%$ CI 143 to 164 days) (Table 4). These wait times were significantly longer than those reported in the 2005 PAGE survey $(\mathrm{P}<0.05)$ (Table 4). The median total wait time for patients who received same-day C\&P was also significantly longer in the SAGE versus PAGE survey $(\mathrm{P}<0.05)$.

Consultation, procedure and total wait times were significantly longer in teaching hospitals than in community-based practices $(\mathrm{P}<0.05)$ (Table 4$)$. However, there was no significant difference in median total wait times by practice type for patients who received same-day C\&P (113 days versus 87 days).

\section{Wait times according to indication}

Median wait times according to the primary indication are shown in Table 5. There were very small numbers of patients for some indications - those with fewer than 10 patients were not analyzed. As expected, longer wait times were encountered for patients receiving screening colonoscopy and those referred for surveillance of previous colon cancer or colon polyps (Table 5). The shortest wait times occurred for those receiving separate or same-day C\&P for 'cancer likely based on imaging or physical examination', severe or rapidly progressing dysphagia or odynophagia, documented iron-deficiency anemia, or dyspepsia with alarm symptoms.

When analyzing the change in wait times from PAGE to SAGE, seven indications provided national data for comparison: poorly-controlled reflux/dyspepsia, with no alarm symptoms; dyspepsia with alarm symptoms; clinical features of significant, active inflammatory bowel disease; chronic diarrhea or chronic constipation; documented iron-deficiency anemia; positive fecal occult blood test; and cancer likely based on imaging or physical examination (Table 5). SAGE total wait times were numerically greater than PAGE data for five of the seven indications and greater than same-day C\&P wait times for all seven indications. In patients with 'cancer likely based on imaging or physical examination', median wait times across all four categories (time to consult, time to procedure, total wait time and same-day C\&P) were significantly longer in SAGE than in PAGE. The median time to consult was significantly longer for patients with 'poorly-controlled reflux/dyspepsia with no alarm symptoms', 'chronic diarrhea or chronic constipation', and 'documented iron-deficiency anemia'. The median total wait time was significantly longer for patients with 'chronic diarrhea or chronic constipation', and the median wait time for same-day C\&P was also significantly longer for patients with 'documented iron-deficiency anemia'.

\section{DISCUSSION}

Assessment of current wait times for health services across specialties is critical to assist in planning for future health
TABLE 4

Wait times overall for teaching hospital- and community-based practices

\begin{tabular}{lcccc}
\hline & \multicolumn{4}{c}{ Time, days } \\
\cline { 2 - 5 } & $\begin{array}{c}\text { To } \\
\text { consult }\end{array}$ & $\begin{array}{c}\text { To } \\
\text { procedure }\end{array}$ & Total wait & $\begin{array}{c}\text { Same-day } \\
\text { consult and } \\
\text { procedure }\end{array}$ \\
\hline Overall & \multicolumn{4}{c}{} \\
SAGE (2008) & $\mathrm{n}=1824$ & $\mathrm{n}=741$ & $\mathrm{n}=741$ & $\mathrm{n}=436$ \\
& $92^{*}(87-97)$ & $50^{*}(45-55)$ & $155^{*}(143-164)$ & $101^{*}(87-116)$ \\
PAGE (2005) & $\mathrm{n}=3965$ & $\mathrm{n}=846$ & $\mathrm{n}=846$ & $\mathrm{n}=852$ \\
& $69(66-71)$ & $37(31-43)$ & $127(116-140)$ & $55(48-62)$ \\
Affiliation & & & & \\
Teaching & $\mathrm{n}=794$ & $\mathrm{n}=311$ & $\mathrm{n}=311$ & $\mathrm{n}=216$ \\
hospital (2008) & $99^{\dagger}(91-107)$ & $62^{\dagger}(51-66)$ & $169^{\dagger}(150-182)$ & $113(94-128)$ \\
Community & $\mathrm{n}=1020$ & $\mathrm{n}=430$ & $\mathrm{n}=430$ & $\mathrm{n}=210$ \\
(2008) & $83(76-93)$ & $43(36-50)$ & $143(128-159)$ & $87(78-109)$ \\
\hline
\end{tabular}

Data presented as median (95\% Cl). *2008 significantly different from 2005 $(P<0.05) .{ }^{\dagger}$ Teaching hospital affiliation significantly different from communitybased practice $(P<0.05)$. PAGE Practice Audit in GastroEnterolgy; SAGE Survey of Access to GastroEnterology

needs in Canada. The SAGE provides timely and much needed data that reflect current practices in gastroenterology health care delivery across Canada. It was undertaken with minimal survey burden to the specialist during a typical work week, thereby providing representative data to update and compare with data acquired during the PAGE survey (6). These surveys provided data necessary to track trends, and advocate for improved human and technical resources, and examined the issues behind excessive wait times, with the goal of improving wait times and patient access to gastroenterology services in Canada. SAGE offered an improved survey system (more efficient and less costly) than the method used in PAGE. The survey methodology provided a means to capture wait time data that should be applicable to other specialist groups and also allowed for the assessment of wait time trends over intervals of years.

The Fraser Institute's 2006 national waiting list survey (1) identified the median wait times to consult in 12 specialties in Canada. The median time to consult reported in SAGE was 92 days (13.1 weeks) - a figure that was exceeded by only four specialties (plastic surgery, ophthalmology, orthopedic surgery and neurosurgery) in the Fraser Institute's survey.

Similar to the results of the PAGE survey, median total wait times continue to exceed consensus recommended maximal wait time targets (Table 1) (5), even among patients who underwent same-day C\&P. The only exception was for chronic gastroesophageal reflux disease referred for screening endoscopy. Indeed, not only are established targets being exceeded, but the trend over time is toward still longer median wait times $(5,6)$. Clearly, timely access to health care specialists requires improvement.

While we have documented that wait times are excessive, we are unable to establish the reasons for failing to meet the recommended targets. Wait times represent a balance between service demands and the available resources needed to meet those demands. We can speculate on several possible reasons for the observed shortfall. We know that the number of Canadian gastroenterology specialists relative to the general population is low compared with some other countries (8). This would suggest a need for more human resources for gastroenterology specialists. 
TABLE 5

Wait times for selected indications

\begin{tabular}{|c|c|c|c|c|c|}
\hline \multirow[b]{2}{*}{ Indication code } & \multirow[b]{2}{*}{ Year } & \multicolumn{4}{|c|}{ Time, days } \\
\hline & & To consult & To procedure & Total wait & $\begin{array}{l}\text { Same day consult and } \\
\text { procedure }\end{array}$ \\
\hline 1: Severe or rapidly progressing dysphagia or odynophagia & 2008 & $\mathrm{n}=25$ & $\mathrm{n}=12$ & $\mathrm{n}=12$ & $\mathrm{n}=19$ \\
\hline \multirow[t]{2}{*}{ 2: Stable dysphagia that is not severe } & 2008 & $\mathrm{n}=45$ & $n=23$ & $\mathrm{n}=23$ & $\mathrm{n}=20$ \\
\hline & & $90(64-113)$ & $43(32-62)$ & $135(93-189)$ & $68(57-112)$ \\
\hline 3: Chronic GERD referred for screening endoscopy & 2008 & $\mathrm{n}=44$ & $\mathrm{n}=18$ & $\mathrm{n}=18$ & $n=16$ \\
\hline \multirow[t]{4}{*}{ 4: Poorly controlled reflux/dyspepsia, NO alarm symptoms } & 2008 & $n=187$ & $\mathrm{n}=75$ & $\mathrm{n}=75$ & $\mathrm{n}=28$ \\
\hline & & $100 *(92-126)$ & $46(34-62)$ & $163(128-193)$ & $81(51-102)$ \\
\hline & 2005 & $\mathrm{n}=92$ & $n=21$ & $n=21$ & $\mathrm{n}=18$ \\
\hline & & $73(60-92)$ & $34(8-118)$ & $153(52-253)$ & $56(14-133)$ \\
\hline 5: Dyspepsia WITH alarm symptoms & 2008 & $n=52$ & $\mathrm{n}=21$ & $n=21$ & $n=15$ \\
\hline 6: Confirmation of celiac disease by antibody test & & $64(40-127)$ & - & - & - \\
\hline \multirow[t]{2}{*}{ 8: Persistent (>6 months) abnormal liver function tests } & 2008 & $\mathrm{n}=61$ & $\mathrm{n}<10$ & $\mathrm{n}<10$ & $\mathrm{n}<10$ \\
\hline & & $112(81-126)$ & - & - & - \\
\hline \multirow[t]{2}{*}{ 9: Chronic viral hepatitis } & 2008 & $\mathrm{n}=38$ & $\mathrm{n}<10$ & $\mathrm{n}<10$ & $\mathrm{n}<10$ \\
\hline & & $72(44-122)$ & - & - & - \\
\hline \multirow[t]{2}{*}{ 10: Chronic abdominal pain } & 2008 & $n=196$ & $\mathrm{n}=54$ & $\mathrm{n}=54$ & $\mathrm{n}<10$ \\
\hline & & $105(91-119)$ & $44(28-72)$ & $152(104-198)$ & - \\
\hline \multirow[t]{3}{*}{ 11: Clinical features of significant active IBD } & 2008 & $n=116$ & $n=39$ & $n=39$ & $\mathrm{n}=12$ \\
\hline & & $66(48-86)$ & $35(25-60)$ & $120(62-141)$ & $74(25-148)$ \\
\hline & 2005 & $\mathrm{n}=50$ & $\mathrm{n}=10$ & $\mathrm{n}=10$ & $\mathrm{n}=10$ \\
\hline \multirow[t]{2}{*}{ 14: Bright red rectal bleeding } & 2008 & $n=159$ & $\mathrm{n}=81$ & $n=81$ & $\mathrm{n}=50$ \\
\hline & & $58(46-75)$ & $54(34-67)$ & $136(107-161)$ & $87(56-134)$ \\
\hline \multirow[t]{4}{*}{ 15: Documented iron-deficiency anemia } & 2008 & $n=104$ & $\mathrm{n}=50$ & $\mathrm{n}=50$ & $\mathrm{n}=28$ \\
\hline & & $56^{*}(38-71)$ & $35(25-64)$ & $90(70-137)$ & $68^{*}(30-123)$ \\
\hline & 2005 & $n=201$ & $n=58$ & $n=58$ & $\mathrm{n}=48$ \\
\hline & & $42(29-53)$ & $18(10-43)$ & $77(33-100)$ & $24(14-56)$ \\
\hline \multirow[t]{4}{*}{ 16: Positive fecal occult blood test } & 2008 & $\mathrm{n}=65$ & $\mathrm{n}=30$ & $\mathrm{n}=30$ & $\mathrm{n}=14$ \\
\hline & & $77(61-92)$ & $41(30-82)$ & $143(122-219)$ & $77(20-136)$ \\
\hline & 2005 & $\mathrm{n}=97$ & $\mathrm{n}=23$ & $n=23$ & $\mathrm{n}=28$ \\
\hline & & $57(45-78)$ & $35(21-57)$ & $97(70-155)$ & $23(18-55)$ \\
\hline \multirow[t]{2}{*}{ 17: Screening colonoscopy } & 2008 & $n=309$ & $n=160$ & $n=160$ & $n=128$ \\
\hline & & $127(116-142)$ & $72(61-93)$ & $201(179-240)$ & $201(173 v 250)$ \\
\hline 18: Cancer likely based on imaging or physical examination & 2008 & $\mathrm{n}=37$ & $\mathrm{n}=16$ & $n=16$ & $n=28$ \\
\hline & & $72^{*}(33-107)$ & $36^{*}(12-57)$ & $82^{*}(34-170)$ & $21^{*}(12-78)$ \\
\hline & 2005 & $\mathrm{n}=53$ & $\mathrm{n}=10$ & $\mathrm{n}=10$ & $\mathrm{n}=41$ \\
\hline & & $14(7-23)$ & $5(1-16)$ & $9(3-75)$ & $13(5-26)$ \\
\hline 19: Other, mostly biliary in nature & 2008 & $\mathrm{n}=12$ & $\mathrm{n}<10$ & $\mathrm{n}<10$ & $\mathrm{n}<10$ \\
\hline & & $23(15-87)$ & - & - & - \\
\hline 20: Surveillance for previous colon cancer or colon polyps & 2008 & $\mathrm{n}=37$ & $n=23$ & $\mathrm{n}=23$ & $\mathrm{n}=19$ \\
\hline & & $92(67-122)$ & $88(69-201)$ & $272(189-345)$ & $176(116-372)$ \\
\hline
\end{tabular}

Data presented as median $(95 \% \mathrm{Cl})$. *2008 significantly different from $2005(P<0.05)$. GERD Gastroesophageal reflux disease; IBD Inflammatory bowel disease 
It is also possible that Canadian primary care physicians are referring patients to a gastroenterologist at higher rates relative to their counterparts elsewhere. We cannot determine whether Canadian gastroenterology specialists are working more or less efficiently than those in other countries. In particular, we cannot assess whether they have sufficient access to endoscopic facilities and are using these facilities appropriately.

There is evidence that these factors are important determinants of access. A United States cohort study (9) of 498 consecutive wait-listed patients referred to an endoscopy practice found $28 \%$ to be inappropriately referred according to published guidelines for appropriate colonoscopy indications. A United Kingdom survey (10) of referred patients $(\mathrm{n}=598)$ wait-listed for follow-up regarding colorectal polyps found that only $14.8 \%$ of cases were being followed up according to guidelines. The majority of patients ( $78 \%$ of low-risk patients and $55 \%$ of intermediate-risk patients) had received or were waiting for a colonoscopy too soon or too frequently according to guideline recommendations. In a United Kingdom survey of 3549 patients currently waiting for a colonoscopy (11), implementation of guidelines led to reductions in wait time for diagnostic colonoscopy from 12 to four weeks for urgent, and from 40 to 15 weeks for routine referrals. Appropriate physician and patient education, provision of validated referral tools and monitoring of adherence to screening practices may liberate some of the time needed to improve patient access to gastroenterologists in Canada.

Compared with the community-based settings, the significantly longer median wait times in teaching hospitals suggest that increasing the number of independent, stand-alone clinics could potentially reduce gastroenterological wait times. Alternatively, the patients seen in teaching hospitals may require different, more time-intensive care or the competing demands of an academic practice may limit patient access to referral centres.

The SAGE has several limitations. Not all eligible physicians participated in the survey and, therefore, bias may have been introduced by physicians who were too busy (may have had longer wait times), were not comfortable sharing their

\section{REFERENCES}

1. Esmail N, Walker M, Wrona D. Waiting your turn, 16th edn. Hospital waiting lists in Canada. The Fraser Institute. Last Update 2006. < http://www.fraserinstitute.org/Commerce.Web/product_files/ wyt2006.pdf $>$ (Version current at June 19, 2009).

2. Sanmartin C, Gendron F, Berthelon J-M, et al. Access to health care services in Canada. Health Analysis and Measurement Group, Statistics Canada. Last Update 2003. <http://www.statcan.ca/ english/freepub/82-575-XIE/2003001/pdf/report.pdf $>$ (Version current at January 19, 2009).

3. Health Canada. A 10-year plan to strengthen health care. Last Update 2004. <http://www.hc-sc.gc.ca/hcs-sss/delivery-prestation/ fptcollab/2004-fmm-rpm/nr-cp_9_16_2-eng.php> (Version current at June 19, 2009).

4. Wait Time Alliance. Time for Progress: New benchmarks for achieving meaningful reductions in wait times. Canadian Medical Association. Last Update 2007. < http://www.waittimealliance.ca/> (Version current at June 19, 2009).

5. Paterson WG, Depew WT, Pare P, et al. Canadian consensus on personal or patient data, or were worried that the data may negatively impact their ability to practice. However, we estimate that more than $40 \%$ of physicians performing gastroenterology procedures (226 of an estimated 550 in Canada [8]) participated in the present survey, making it a highly representative sample. In addition, because physicians were given the option to remain anonymous, concerns over sharing data should have been avoided. The survey was conducted during one specific week, while this has the benefit of providing a snapshot of wait times at a particular moment, unknown factors during the week in question could have skewed the results. The data do not reflect wait times for those specializing in liver diseases only, which may be associated with longer wait times. Although wait times were self-reported by physicians, there was no reason to suspect differential reporting in 2008 compared with 2005. In the present paper, we did not examine the 75 th or other percentiles of wait times -75 th percentiles can provide valuable information because they indicate wait times for $25 \%$ of the patients who wait the longest.

\section{SUMMARY}

The SAGE provides a snapshot of access to gastroenterology services by Canadians in 2008. Compared with an earlier survey conducted in 2005 (PAGE), wait times have not improved and have, in fact, become longer. In both surveys, wait times for many indications exceeded consensus conference recommended targets. Future research should attempt to examine the causes of the increase in wait times so that appropriate strategies can be developed to improve patient access. The goal is to provide timely access to high-quality digestive health services across Canada. We have established a methodology for measurement of point-of-access care wait times that is applicable to other groups.

ACKNOWLEDGEMENTS: The authors thank Sandra Daniels and Palma Colacino for organizational support and Pauline Lavigne for editorial assistance.

medically acceptable wait times for digestive health care. Can J Gastroenterol 2006;20:411-23.

6. Armstrong D, Barkun AN, Chen Y, et al. Access to specialist gastroenterology care in Canada: The Practice Audit in Gastroenterology (PAGE) Wait Times Program.

Can J Gastroenterol 2008;22:155-60.

7. Leddin D, Armstrong D, Barkun AN, et al. Access to specialist gastroenterology care in Canada: Comparison of wait times and consensus targets. Can J Gastroenterol 2008;22:161-7.

8. Moayyedi P, Tepper J, Hilsden R, et al. International comparisons of manpower in gastroenterology. Am J Gastroenterol 2007;102:478-81.

9. Baron TH, Kimery BD, Sorbi D, et al. Strategies to address increased demand for colonoscopy: Guidelines in an open endoscopy practice. Clin Gastroenterol Hepatol 2004;2:178-82.

10. Pickard M, Dewar EP, Kapadia RC, et al. Follow up of patients with colorectal polyps: Are the BSG guidelines being adhered to? Colorectal Dis 2007;9:203-6.

11. Shoaib A, Hamade A, Zia A, et al. Why wait for a colonoscopy? An easy cure. Colorectal Dis 2006;8:480-3. 


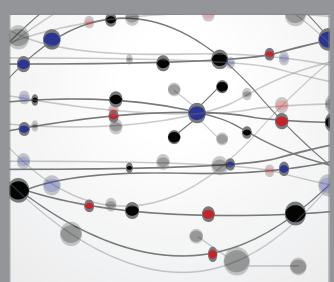

The Scientific World Journal
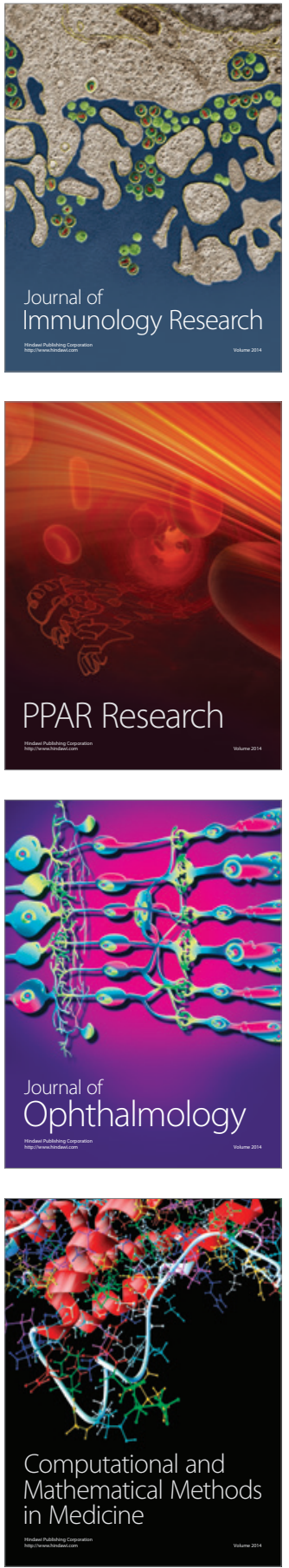

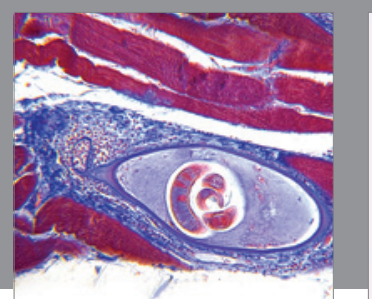

Gastroenterology Research and Practice

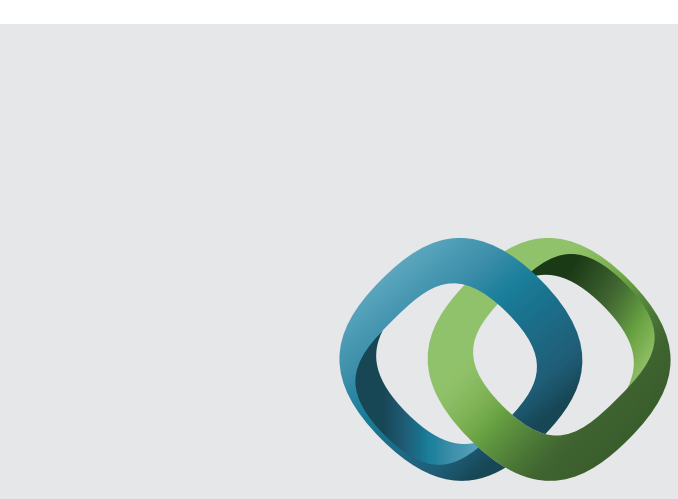

\section{Hindawi}

Submit your manuscripts at

http://www.hindawi.com
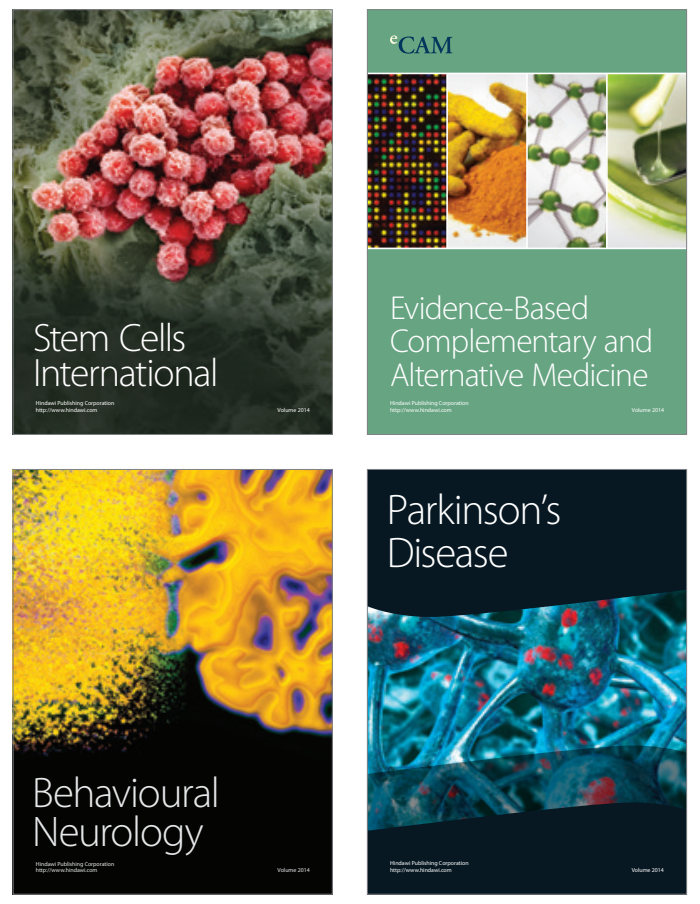
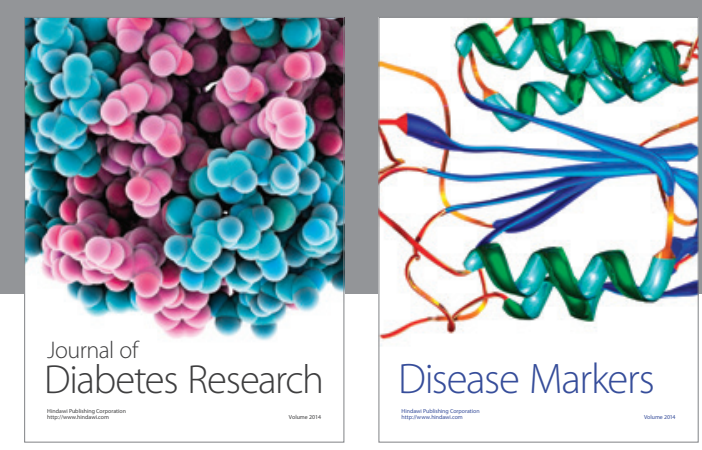

Disease Markers
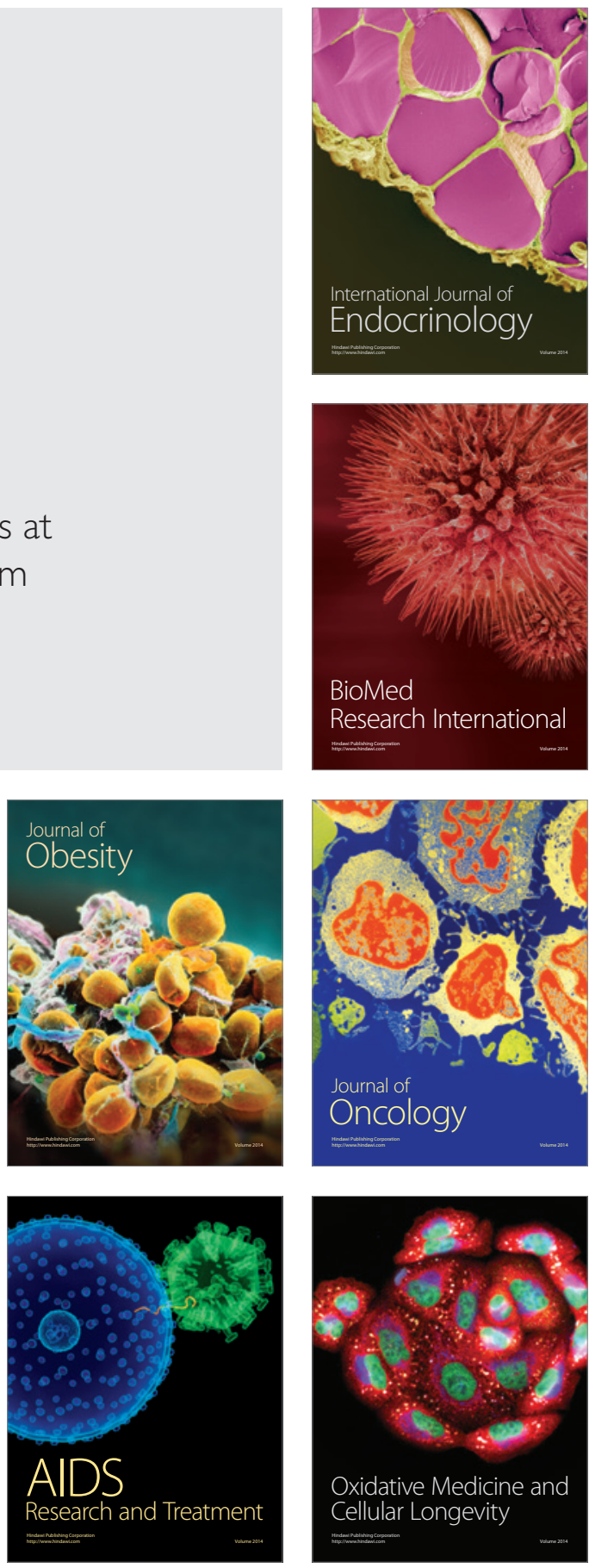